\title{
Serological Analyses of Human Brucellosis in Ngara and Kibondo Districts, Tanzania
}

\author{
Jestina V Katandukila ${ }^{\mathbf{1}}$, Yeremia J Chuhila ${ }^{\mathbf{1}}$ and Fred D Chibwana ${ }^{\mathbf{1}}$ \\ ${ }^{l}$ Department of Zoology and Wildlife Conservation, University of Dar es Salaam, \\ P. O. Box 35064, Dar es Salaam, Tanzania.
}

*Corresponding author, e-mail: jestina.katandukila2@gmail.com; jestina@udsm.ac.tz Received 8 Mar 2021, Revised 4 Aug 2021, Accepted 5 Aug 2021, Published Aug 2021

DOI: https://dx.doi.org/10.4314/tjs.v47i3.30

\begin{abstract}
Brucellosis, a zoonotic disease transmitted by Brucella species, is transmitted to humans from infected animals through handling dairy products like milk, blood, and semen. Although some human communities in Tanzania live close to livestock, the status of human brucellosis in Ngara and Kibondo Districts in Kagera and Kigoma regions, respectively, is poorly understood. As such, the present study aimed to investigate the status of human brucellosis in north-western Tanzania, particularly Ngara and Kibondo Districts, where the risk of contracting zoonotic diseases, including brucellosis, is high due to the abundance of livestock. Among the screened sera ( $\mathrm{n}=$ 450), the prevalence was $13.11 \%$ with an incidence rate of $6.22 \%$ in 581,378 population size intimating that the risk is alarming. Brucellosis patients admitted in dispensaries and other lower health facilities ranged from $6 \%$ to $26 \%$, while those admitted in hospitals ranged from $4 \%$ to $14 \%$ indicating that communities prefer primary health facilities to hospitals when they show symptoms of brucellosis. The present study has also revealed that communities engaged in slaughtering, milking, skinning and helpers during births of livestock are at high risk of acquiring Brucella spp. because the odds ratios' of these activities range between 1.583 and 8.400 . Therefore, awareness and education should be enhanced by veterinary officers and associated stakeholders. A comprehensive study of brucellosis using molecular techniques to reveal species-specific in northwestern Tanzania is highly recommended.
\end{abstract}

Keywords: brucellosis, prevalence, incidence, risk factors, serum.

\section{Introduction}

Brucellosis is a contagious disease caused by zoonotic bacteria of the genus Brucella with its symptoms mimic those of malaria, typhus, and typhoid, whereas a patient develops fever, headache, weakness, body aches, and pains (Seleem et al. 2010, Cash-Goldwasser et al. 2018). Brucellosis has been reported to depress the human immune system since it causes fever which may consequently lead to immune suppression (Corbel 2006, Franco et al. 2007). The Brucella bacteria are transmitted from animals to humans by ingestion of infected food sources (i.e. raw and undercooked meat) and direct contact with an infected animal or the secretions including milk, blood, urine and semen (Doganay and Aygen 2003, Tuon et al. 2017). Moreover, activities related to the handling of animal fluids such as slaughtering, milking and skinning have also been reported to be the major sources of transmission of the brucellosis (Corbel 2006, Swai and Schoonman 2009). In this case, people engaged in activities such as livestock keeping, abattoir and pastoralism are reported to be at high risk 
of being infected with the disease (Tumwine et al. 2015).

Animals reported transmitting brucellosis include cattle, sheep, swine, dogs, goats, bison, elks, caribous and canids (Garin-Bastuji et al. 2006, Blasco and Molina-Flores 2011). Owing to the high interactions between domestic animals and their keepers (i.e. humans) as well as with wild animals in water drinking sites, close niche for sleeping and foraging, little is known on the prevalence of brucellosis in pastoral communities. Several studies, investigating the prevalence of contagious diseases in communities of livestock keepers have been conducted in north-western Tanzania (Kandusi 2016, Tarimo 2017, Ntirandekura et al. 2018, Mgode et al. 2019, Thickstun 2019) but none of them is known to focus on brucellosis, notably in Kagera and Kigoma regions. In these regions, most of the families keep livestock without an idea of zoonotic diseases that may be transmitted to them (Kifaro et al. 2014, Forbes and Kepe 2015, Ntirandekura et al. 2018). Animals kept in these areas include cattle, sheep, goats, dogs and pigs.

The objective of this study was to screen human brucellosis since the communities are keeping animals in closer vicinity to their houses and sometimes they use the same house. The screening of human brucellosis may enlighten on the status of zoonotic diseases in the ecosystem and their prevalence. The study hypothesized that the significant prevalence of human brucellosis is a result of high humananimal interactions. The screening of brucellosis employed Rose Bengal Plate Test (RBPT) and Tube Serum Agglutination Test (SAT). These serological methods have been recommended to be useful in the investigation of brucellosis using blood serum (Chachra et al. 2009, Islam et al. 2013, Yohannes et al. 2012, Gusi et al. 2019). Although the development of PCR-based diagnostic tools has presented a new dimension in the detection of human brucellosis, procedural simplification for detecting brucellosis at the species level in standard laboratories and their associated costs are challenging (Navarro et al. 2004). As such, to date, the diagnostic tools for detection of brucellosis species-specific are still a challenge as co-pathognomic symptoms mimic other epidemic and pandemic diseases (Kerr et al. 1966, De la Vega et al. 2000, Teng et al. 2017).

\section{Materials and Methods \\ Study area and sites}

This study was conducted in Ngara District in the Kagera region and Kibondo District in the Kigoma region (Figure 1). Ngara District is one of the nine Districts forming the Kagera region. It is located in the northwest of Tanzania at about $1,800 \mathrm{~m}$ above sea level at $30^{\circ} 45^{\prime} \mathrm{S}$ and $30^{\circ} 40^{\prime} \mathrm{E}$ (Kagera Region Investment Guide 2019). The estimated population size of Ngara District is 320,056 people (NBS 2012). The major economic activities in the District include agriculture (coffee and banana farming), large-scale livestock keeping and tourism. Like other Districts in the Kagera region, Ngara has a tropical climate characterized by bimodal rainfall between October to November and March to May and its mean annual rainfall is about $900 \mathrm{~mm}$ (ranging between 600 and 1,200 $\mathrm{mm}$ ). The mean annual temperature is $21{ }^{\circ} \mathrm{C}$ (ranging between 20 and $30{ }^{\circ} \mathrm{C}$ ). The study sites within Ngara Districts were Mabawe Health Centre, Nyamiaga District Hospital, Kabanga Dispensary and Murukukumbo village (Note: Murukukumbo village is not a health centre but livestock keepers requested to be screened after sensitization during blood sampling for livestock. Special arrangements with Kabanga Dispensary Authority was done and visited the village with laboratory personnel who were responsible for blood drawing from humans following stipulated protocols on NIMR guidelines). Kibondo District on the other hand, is one of the six Districts of the Kigoma region. It is located in northwestern Tanzania sharing an international border with Burundi in the north-west, Kakonko District in the north, Kasulu District in the west, Tabora region in the east and Uvinza District in the south. The District is 
located at $4^{\circ} \mathrm{S}$ and $31^{\circ} \mathrm{E}$ in $1254 \mathrm{~m}$ from the sea level. The estimated population size of Kibondo District is 261,331 people (NBS 2012). The Kibondo District receives an annual rainfall of about $900 \mathrm{~mm}$ (ranges between 600 and 1,000 $\mathrm{mm}$ ) and an average temperature of 24.6 ${ }^{\circ} \mathrm{C}$ (Kigoma Region Socio-Economic Profile 2016). The main economic activities in the District include agriculture, livestock keeping and honey production. The study sites in Kibondo were Kibondo District Hospital, Minyinya Dispensary, Kifura Dispensary, Kitahana Dispensary and Twabagondozi Dispensary.

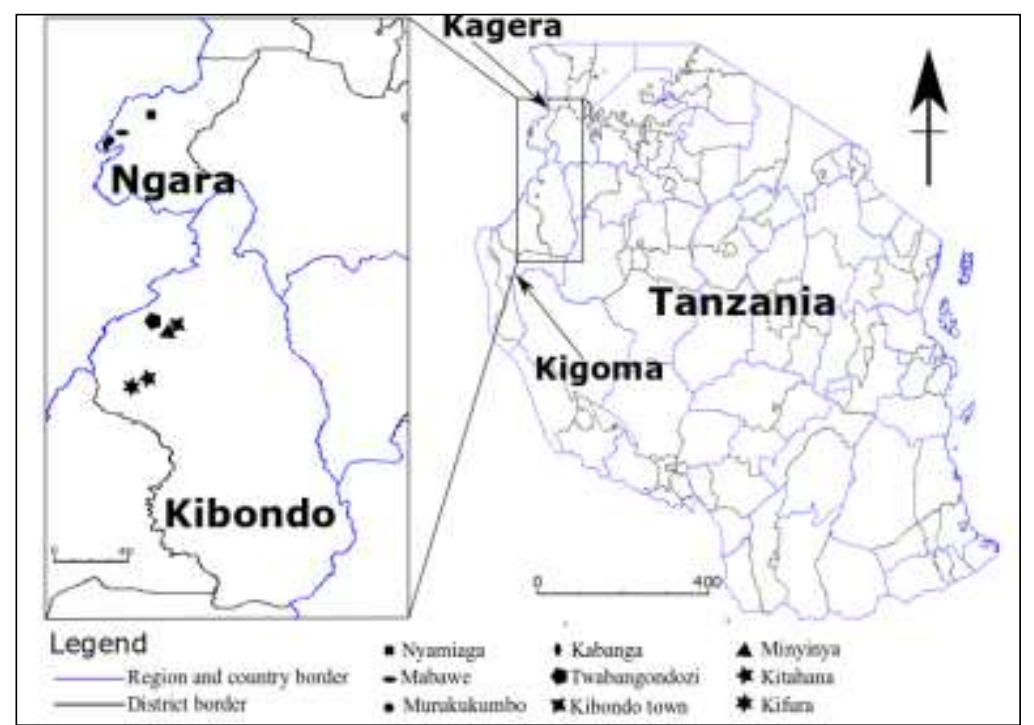

Figure 1: Map of Tanzania showing the study sites for investigation of brucellosis in selected areas of Kigoma and Kagera regions.

\section{Sample size}

The number of individuals involved in the survey was determined by the equation $\boldsymbol{N}=\boldsymbol{n} \boldsymbol{x} \boldsymbol{D}$ as detailed by Bennett et al. (1991), Daniel (1999) and Naing et al. (2006) with little modification whereby,

$$
\begin{gathered}
n=\frac{Z^{2} x P(1-P) Z^{2}}{d^{2}} \text { and } \\
D=1+(1-b) R O H
\end{gathered}
$$

where: $\mathbf{n}=$ sample size without design effect; $\mathbf{N}=$ corrected sample size; $\mathbf{Z}=$ test statistic; $\mathbf{P}$ = expected prevalence; $\mathbf{d}=$ precision; $\mathbf{D}=$ design effect; $\mathbf{b}=$ mean number of people in a cluster; and $\mathbf{R O H}=$ rate of homogeneity. For our study, $\mathrm{Z}=1.96 ; \mathrm{P}=6 \% ; \mathrm{d}=0.03 ; \mathrm{b}=5$ and $\mathrm{ROH}=0.08$ (i.e. values harmonized from the above-mentioned studies). Based on the formula above, the estimated population size for this study was 440 participants.

\section{Sample collection}

Blood serum was obtained after the separation of the supernatant of blood drawn from humans. The blood samples were collected from hospitalized and nonhospitalized patients who visited the dispensaries, health centres and hospitals on the day of data collection. Before the donation of blood for the study, participants were sensitized to broaden their awareness of zoonoses and their impacts on human health and socio-economic activities. After the sensitization, participants were asked for their consent and signing the consent forms as per 
guidelines and rules on the collection of samples from humans as stipulated on the permit we obtained from the National Institute of Medical Research (NIMR) with permit no NIMR/HQ/R.8a/Vol.IX/2951. Blood samples were also collected in asymptomatic humans who did not visit the hospitals, dispensary or health centres but engaged in livestock keeping or slaughtering or frequently used animal products including meat, milk, and processing skins. The study also included blood samples from people involved in skinning wild animals from Kigosi-Muyowosi Game Reserve. Blood samples from humans were drawn using vacutainers and labelled with specific codes. The blood was drawn by laboratory technicians assigned by the District Health Committee within their respective health facilities. The blood was stored in a vacutainer to settle for 45 minutes before removing the serum. the serum was stored at $-20{ }^{\circ} \mathrm{C}$ following standard protocols (Cho et al. 2010).

In the laboratory, the blood serum was allowed to thaw and vortexed to get a uniform concentration. Rose Bengal antigen $(50 \mu)$ was pipetted in a well of a microtitre plate and subsequently, the same amount of serum was added and mixed thoroughly and the solution was kept at room temperature for 5 minutes (Baek et al. 2000) before the microscopic observation. Three replicates were made per sample for precision during the microscopic screening (Brinley-Morgan et al. 1969). The viewing of the presence or absence of agglutination was done under a dark-filled microscope in which samples with agglutinations were considered positive (Díaz et al. 2011). The highest titre volume for Rose Bengal Plate Test (RBPT) was 1:20. Similar samples were subsequently subjected to the
Serum Agglutination Test (SAT) which is a confirmatory test for the presence of brucellosis as it detects Brucella antibodies in serum (Ardo et al. 2016). With SAT, the 100 microlitres of the solution of Brucella antigen and Safranin were kept in wells of a microtitre plate, and subsequently, the same amount of serum was added, mixed thoroughly and labelled accordingly. The solution was kept at $37{ }^{\circ} \mathrm{C}$ for 24 hours before screening for the presence or absence of agglutination; agglutinated samples were considered positive, while non-agglutinated samples were considered negative (McGiven et al. 2003).

\section{Assessment of awareness and risk factors associated with the spread of Brucellosis}

The awareness towards brucellosis was assessed using structured and unstructured questionnaires basing on demographic information, existing knowledge of brucellosis, the known cases of brucellosis infections, perception towards brucellosis infections, preventive and control measures, the effectiveness of the current control measures, public interventions, and accessibility to public health facilities. The assessment of risk factors associated with transmission of brucellosis was done by associating the results of sera with the socio-economic activities of the participant, the information that was collected during the questionnaire survey. The major socioeconomic activities considered included slaughtering, milking, butchering, semen transfer and helping miscarries and helping deliveries (Corbel 2006). The selection of these factors was based on the lifestyles of participants within the studied ecosystem (Figure 2). 

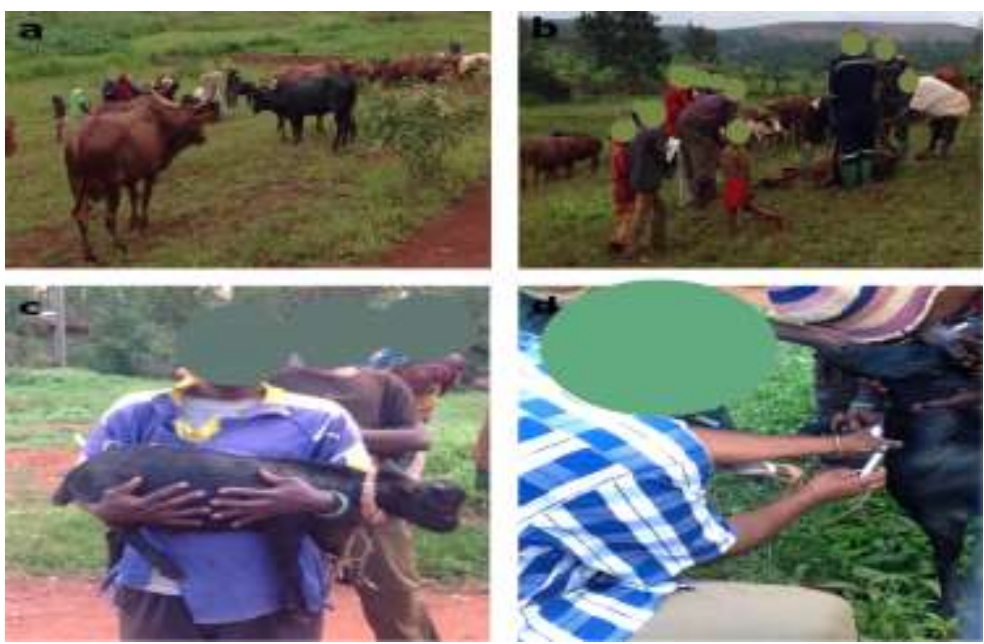

Figure 2: Impressions from selected animal handling activities in Ngara and Kibondo. a) Delivery assistance in the foraging area (Kibondo). b) local insemination (Kibondo). c) Improper handling of animals by herdsmen (Ngara). d) Handling animals without protective gear (Ngara). (Photo credit: J.V. Katandukila \& J. Chuhila).

\section{Data analysis}

The information from questionnaires and interviews were subjected to Statistical Package for Social Sciences (SPSS) version 21 (IBM Corporation 2013). The numerical data were not normally distributed, and thus statistics and comparisons between the aspects were evaluated by non-parametric statistical tests. The selected demographic information and extent of awareness of brucellosis were presented as percentages. The strength of risk factors for associated socio-economic activities on infection of brucellosis was evaluated by Logistic Regression Model with the assumption that socio-economic activities may expose humans to infections or no-infection. The logistic regression model used was

$$
P=\frac{1}{1+e^{-(\beta 0+\beta 1 \times 1)}}
$$

where $\mathrm{P}=$ Probability; $\beta 0=$ Intercept of the model; $\beta 1 \times 1=$ slope. For the present study, the $\beta 0=-2.4819$ and $\beta 1=0.0588$. The strength of risk associated with socio-economic activities is presented by the odds ratio. Quantitive data were subjected to $\mathrm{R}$ algorithm version 3.4.2 ( $\mathrm{R}$ Core Team 2017). The normality was evaluated by Shapiro Wilk test
$\left(\mathrm{W}_{\text {(Ngara District) }}=0.928, \mathrm{P}=0.327\right.$ and $\mathrm{W}_{\text {(Kibondo }}$ District) $=0.768, \mathrm{P}=0.026)$. The prevalence and incidence rate of brucellosis was evaluated by the standard formula in epidemiology and presented as percentage. Evaluation of incidence rate in-corporated population size of studies ecosystem (note: see population size study site descriptions above). The incidence rate was evaluated as $I R=[(N C \div P R) \times P S] \times 100 \%$, whereas IR $=$ Incidence rate; $\mathrm{NC}=\mathrm{New}$ cases; $\mathrm{PR}=$ Population at risk; PS = Population size. Comparison of variables was determined by Mann-Whitney test, chi-square and $t$ statistical tests. The significance level for all statistical tests was at $\alpha=0.05$.

\section{Ethical approval note}

The study was approved by the University of Dar es Salaam (certificate no. CoNASZLW18058), National Institute of Medical Research (NIMR: NIMR/HQ/R.8a/Vol.IX/2951) and the Commission of Science and Technology (no. 2019-84-NA-2018-387). 


\section{Results}

Awareness of participants on
brucellosis

Majority $(90 \%)$ of the respondents $(n=600)$ showed awareness of zoonotic transmitted diseases, of which females represented $59.3 \%$ and males were $30.7 \%$. Zoonotic diseases of great awareness in the ecosystem were sarcoptic mange $(53.8 \%)$, lyme $(23.1 \%)$, rabies $(11 \%)$, plague $(7.2 \%)$, brucellosis $(3.5 \%)$ and leptospirosis $(1.4 \%)$. Among the avenues for awareness of zoonotic diseases including brucellosis were media which contributed the highest percentage of the awareness (67.72\%), followed by sensitization of veterinary officers $(22.03 \%)$ and school education by $5 \%$. The awareness of the preventive measures on brucellosis showed $4 \%$, while unawareness showed $96 \%$.

\section{Assessment of risk factors on transmission of brucellosis}

Selected socio-economic activities associated with the risks of the transmission of brucellosis included helping animals during miscarriage delivery, slaughtering, skinning, milking. Among the selected factors, helping animals during miscarriage delivery showed the highest odds ratio compared to milking and semen induction that showed the lowest values (Table 1). Comparison of pooled odds ratios' of activities related to the transmission of brucellosis varied significantly $\left(\chi_{(1)}^{2}=14.2547\right.$, $\mathrm{P}=0.0002)$, while the variation of odds ratios between Districts was insignificant $(\mathrm{U}=24.5$, $\mathrm{P}<0.05 \mathrm{n}_{1}=7, \mathrm{n}_{2}=7$ ).

Table 1: Odds ratios and critical values of selected socio-economic activities in association to infections of brucellosis in Ngara and Kibondo Districts. Pvalue = Probability value; CI $=$ confidence interval (Data collected in the year 2018-2019)

\begin{tabular}{lccc}
\hline Socio-economic activity & Odds ratio & P value & 95\% CI \\
\hline Slaughtering & 3.29 & 0.0010 & $1.8582-5.8116$ \\
Milking & 1.54 & 0.2424 & $0.9026-2.5620$ \\
Help miscarries & 8.40 & $<0.0001$ & $1.3446-52.4781$ \\
Skinning & 5.00 & 0.0014 & $1.9014-13.1482$ \\
Help deliveries & 5.14 & $<0.0001$ & $2.3953-11.0305$ \\
Butchery & 1.96 & 0.0101 & $0.4475-8.5708$ \\
Semen induction & 1.80 & 0.1003 & $0.6536-5.3788$ \\
\hline
\end{tabular}

\section{Rose Bengal Plate Test (RBPT)}

A total of 450 sera (i.e. $n=200$ from Ngara District and $\mathrm{n}=250$ from Kibondo District) were screened for the presence of Brucella species. Out of the 450 sera, $13.11 \%$ were positive for RBPT. The seroprevalence of Brucella was $18.5 \%$ in the Ngara District in which females showed a high prevalence of $54.05 \%$ with males showed $45.95 \%$. In Kibondo District, the seroprevalence was $8.8 \%$ with females showed $45.45 \%$, while males showed a higher prevalence of $54.55 \%$. Among the surveyed health facilities in Ngara Districts, the sera collected in the Kabanga Dispensary had the highest seropositive, with Nyamiaga
District Hospital and Murukukumbo showing lowest seroprevalence (Table 2) although the variation was insignificant $\left(\chi^{2}{ }_{(6)}=7.634, \mathrm{P}=\right.$ 0.266). In Ngara District, females showed higher prevalence almost in all the health facilities than males although the variation was statistically insignificant $\left(\chi_{(1)}^{2}=2.658, \mathrm{P}=\right.$ 0.103). In Kibondo District, seroprevalence was higher in Minyinya Dispensary, while sera from Kibondo District Hospital showed the lowest prevalence (Table 2). Comparison of seroprevalence between health facilities in Kibondo District was statistically insignificant $\left(\mathrm{U}=0.02, \mathrm{P}=0.999 ; \mathrm{n}_{1}=4, \mathrm{n}_{2}=5\right)$. 
Table 2: Sero-prevalence of brucellosis in various health facilities visited in Ngara and Kibondo Districts. The sample size was 50 participants per study site (i.e. health facility) in which males were 25 and females were 25. (Data collected in the year 2018-2019)

\begin{tabular}{|c|c|c|c|c|c|c|}
\hline \multirow[t]{3}{*}{ District } & \multirow[t]{3}{*}{ Health facility } & \multicolumn{5}{|c|}{ Sero-prevalence (\%) } \\
\hline & & \multirow[t]{2}{*}{$\begin{array}{l}\text { Sexes } \\
\text { pooled }\end{array}$} & \multicolumn{2}{|c|}{ Sexes separated } & \multicolumn{2}{|c|}{$\begin{array}{l}\text { Sexes separated within } \\
\text { health facility }\end{array}$} \\
\hline & & & Females & Males & Females & Males \\
\hline \multirow[t]{4}{*}{ Ngara } & Kabanga & 26 & 12 & 14 & 24 & 28 \\
\hline & Mabawe & 22 & 10 & 12 & 20 & 24 \\
\hline & Nyamiaga & 14 & 12 & 2 & 24 & 4 \\
\hline & Murukukumbo & 12 & 6 & 6 & 12 & 12 \\
\hline \multirow[t]{5}{*}{ Kibondo } & Minyinya & 16 & 6 & 10 & 12 & 20 \\
\hline & Kitahana & 6 & 2 & 4 & 4 & 8 \\
\hline & Kifura & 12 & 6 & 6 & 12 & 12 \\
\hline & Twabangondozi & 6 & 6 & 0 & 12 & 0 \\
\hline & Kibondo town & 4 & 0 & 4 & 0 & 8 \\
\hline
\end{tabular}

\section{Serum Agglutination Test (SAT)}

Among the 59 positive sera from RBPT, 28 sera $(6.22 \%, \mathrm{n}=450)$ were also positive in SAT. Sera from Ngara District showed incidence rate of $8.5 \%(\mathrm{n}=200)$, while Kibondo District showed incidence rate of $4.4 \%(\mathrm{n}=250)$. Females had a higher seroprevalence of brucellosis by having $76.47 \%$, while males had a higher seroprevalence of $54.55 \%$ in Ngara and Kibondo Districts, respectively (Table 3). The comparison of seroprevalence between health facilities and sexes in Kibondo Districts variation was insignificant $\left(t_{(4)}=0.918, \mathrm{P}=\right.$ 0.411 ), while the sexes varied significantly in Ngara District (facilities: $\mathrm{X}^{2}{ }_{(3)}=8.402, \mathrm{P}=$ $0.024)$ with insignificant variation between facilities $\left(\mathrm{X}_{(3)}^{2}=7.586 \mathrm{P}=0.055\right)$.

Table 3: The sero-incidence of brucellosis in various health facilities visited in Ngara and Kibondo Districts. The sample size was 50 participants per sample site (i.e. health facility) in which males were 25 and females were 25. (Data collected in the year 20182019)

\begin{tabular}{llccccc}
\hline District & Health facility & \multicolumn{4}{c}{ Sero-prevalence (\%) } \\
\cline { 3 - 7 } & & $\begin{array}{l}\text { Sexes } \\
\text { pooled }\end{array}$ & \multicolumn{2}{c}{ Sexes separated } & \multicolumn{2}{c}{$\begin{array}{c}\text { Per sexes within } \\
\text { the health facility }\end{array}$} \\
\cline { 3 - 7 } Ngara & & females & males & Females & Males \\
& Kabanga & 16 & 12 & 4 & 24 & 8 \\
& Mabawe & 8 & 6 & 2 & 12 & 4 \\
& Nyamiaga & 6 & 6 & 0 & 12 & 0 \\
& Murukukumbo & 4 & 2 & 2 & 4 & 4 \\
& Minyinya & 4 & 2 & 2 & 4 & 4 \\
& Kitahana & 4 & 0 & 4 & 0 & 8 \\
& Kifura & 6 & 2 & 4 & 4 & 8 \\
& Twabangondozi & 4 & 4 & 0 & 8 & 0 \\
& Kibondo town & 4 & 2 & 2 & 4 & 4 \\
\hline
\end{tabular}




\section{Discussion}

Brucellosis is a neglected disease with a substantial impact in livestock keepers' communities or frequent users of unhygienic livestock products (Seleem et al. 2010, CashGoldwasser et al. 2018). The limited awareness of brucellosis in pastoral communities is well exposed in the present study as participants had little knowledge of brucellosis and its means of transmission. Little awareness in the transmission of brucellosis among zoonoses may be attributed to its co-pathogenic symptoms such as fever and headache that are co-symptoms of Malaria, typhoid and typhus (De la Vega 2000, Corbel 2006, Franco et al. 2007, Picard-Hagen et al. 2015, Tarimo 2017). Unlike malaria and other contagious diseases, detection of brucellosis is challenging due to limited diagnostic tools (De la Vega 2000, Teng et al. 2017). As a consequence, when participants show co-symptoms are immediately tested for other diseases. Several studies in Tanzania have investigated brucellosis and their consequential impacts on livestock and their products (Weinhäupl et al. 2000, Garin-Bastuji et al. 2006, Swai and Schoonman 2009, Blasco and Molina-Flores 2011), but human-brucellosis is more or less neglected which may be a contributing factor to low brucellosis awareness (Seleem et al. 2010).

Livestock keepers notice the presence of brucellosis when their livestock suffer from frequent miscarriages ( Díaz 2013, Legesse et al. 2018) while unaware of the possible transmission of Brucella species from livestock to humans. Helping livestock during miscarry delivery, normal delivery, skinning, butchery vending without proper protecting tools have been reported to elevate transmission of brucellosis from affected animals to human beings (Swai and Schoonman 2009). Brucellosis has also been reported to be sourced from livestock products such as meat and milk of affected animals when prepared unhygienically (Weinhäupl et al. 2000, Dadar et al. 2019). Since brucellosis cannot be diagnosed by virtual observation, livestock keepers may slaughter affected animal(s) and raw blood users being at high risk of acquiring Brucella spp. Furthermore, unethical semen transfer has been reported to cause transmission of brucellosis between animals and semen inducers (Worthington et al. 1985, Vinodh et al. 2008, Picard-Hagen et al. 2015). Among the victims of brucellosis in northwestern Tanzania are adults of both sexes since are the ones who take care of livestock with youth engaged in contemporary economic activities such as tricycle and motorcycle riding. Similar to observations elsewhere, females' high susceptibility is attributed to traditional and norms that females should undertake care of livestock during gazing and associated activities like milking and cleaning livestock hurts.

The high prevalence and incidences of brucellosis in Ngara and Kibondo Districts is an indication that humans in those Districts interact heavily with Brucella natural reservoir hosts. Brucella species have been reported to be transmitted by domestic animals by touching the body fluid of contaminated domestic animals (Weinhäupl et al. 2000). Consequently, communities having high interactions with animals have high risks of contracting brucellosis as reported elsewhere (Doganay and Aygen 2003, Tumwine et al. 2015, Cash-Goldwasser et al. 2018). In all the sampled areas, in the present study, most of the individuals sampled engaged in livestockrelated activities that expose them to contact animal body fluids including blood, milk and fresh meat. In this study, among others, we sampled slaughters and milk vendors that support the previous observation. Also, it is not surprising to observe the risk factors putting females more susceptible to brucellosis than males as it is their family's responsibility to handle and milk animals.

Dispensaries recorded more participants with brucellosis than hospitals because when people experience symptoms of sickness they seek dispensaries as they are closer to their vicinity and when symptoms persist are referred to higher rank health facilities 
(Dominicus and Akamatsu 1989, Kapologwe et al. 2020). The service provided in dispensaries and health centres may perhaps provide better first aid which assists in reducing the threshold of incidences. It is advised that when people feel the symptoms of fever should visit health centres and dispensaries to be diagnosed, treated to reduce the incidence of diseases including brucellosis (Dominicus and Akamatsu 1989).

Mass communications such as radio, television and newspapers contribute to awareness on contemporary issues including awareness on zoonoses (Tchuenche and Bauch 2012). Besides, elsewhere it has been shown that school curriculum can help create awareness of infectious diseases among school children and the community at large (Jacque et al. 2016). However, despite the noticeable impacts of zoonoses, schools' curriculum in Tanzania lack components of zoonoses, thus even well-educated communities have limited knowledge of brucellosis. Similarly, veterinary officers, who regularly raise awareness of zoonoses in communities with livestock, have focused on other zoonotic diseases neglecting brucellosis.

\section{Conclusion}

These results show that the studied ecosystem (Ngara and Kibondo) has an alarmingly high brucellosis incidence. Since Brucella species are associated with non-human hosts including livestock, handling of husbandry and associated socio-economic activities that may pose a risk of contracting brucellosis thus risk activities should be done carefully using protective equipment/tools. The hygienic preparation of livestock products including meat, dairies and blood should be enhanced. The regular visitation of veterinary officers in the livestock keepers' community should be enhanced as it may increase awareness of cyclic pathogens between humans and livestock including neglected zoonoses. Molecular analysis for Brucella speciesspecific and their genetic structure is recommended to unveil the extent of their molecular diversity.

\section{Funding}

The grant for a study was provided by the University of Dar es Salaam (UDSM) under the project code CoNAS-ZLW18058.

\section{Authors' Contributions}

All authors participated in the conception of the idea, data collection, analysis and manuscript write-up. The manuscript preparation and submission was approved by all authors.

\section{Conflicts of interest}

There is no conflict of interest regarding this paper.

\section{Acknowledgements}

The authors are grateful to Mr Ackrey Sissa of the Department of Zoology and Wildlife Conservation, UDSM for his support during data collection. The specific appreciation is directed to local communities participated, Veterinary Officers of Ngara District (Dr R. Ngowi) and Kibondo District (Mr A. Gotta) for their kindly support during data collection.

\section{References}

Ardo MB, Abubakar DM and Adamu Z 2016 Prevalence of Brucella antibodies in horses (Equus caballus) in Jalingo, Taraba State, Nigeria. J. Public Health Epidemiol. 8: 111-114.

Baek B, Lim K, Hur J and Choi M 2000 Immunological response in pigs immunized with inactivated Brucella suis. Korean J. Vet. Pub. Health 24: 133-142.

Bennett S, Woods T, Liyanage WM and Smith DL 1991 Simplified general method for cluster sample surveys. World Health Stat. Quart. 44: 98-106.

Blasco JM and Molina-Flores B 2011 Control and eradication of Brucella melitensis infection in sheep and goats. Vet. Clin. N. Am. Food Anim. Prac. 27: 95-104.

Brinley-Morgan WJ, MacKinnon DJ, Lawson JR and Cullen GA 1969 Rose Bengal Plate Agglutination Test in the Diagnosis of Brucellosis. Vet. Rec. : 636-641. 
Cash-Goldwasser S, Maze MJ, Rubach MP, Biggs HM, Stoddard RA, Sharples KJ, Halliday JE, Cleaveland S, Shand MC, Mmbaga BT and Muiruri C 2018 Risk factors for human brucellosis in northern Tanzania. Am. J. Trop. Med. Hyg. 98: 598-606.

Chachra D, Saxena HM, Kaur G and Chandra M 2009 Comparative efficacy of Rose Bengal plate test, standard tube agglutination test and Dot ELISA in immunological detection of antibodies to Brucella abortus in sera. Afr. J. Bacteriol. Res. 1: 30-33.

Cho D, Nam H, Kim J, Heo E, Cho Y, Hwang I, Kim J, Kim J, Jung S and More S 2010 Quantitative Rose Bengal test for diagnosis of bovine brucellosis. J. Immun. Immunochem. 31: 120-130.

Corbel MJ 2006 Brucellosis in humans and animals. World Health Organization.

Dadar M, Shahali Y and Whatmore AM 2019 Human brucellosis caused by raw dairy products: a review on the occurrence, major risk factors and prevention. Int. J. Food Microbiol. 292: 39-47.

Daniel WW 1999 Biostatistics: A Foundation for Analysis in the Health Sciences. $7^{\text {th }}$ edition. New York: John Wiley \& Sons. European Commission, 141-142.

De la Vega AC, Cruz ML and Wilde OR 2000 Incidence of antibodies originating from vaccine in animals sero-positive to BPA in the diagnostics of bovine brucellosis. Avance Agroindustr. 21: 37-39.

Díaz A 2013 Epidemiology of brucellosis in domestic animals caused by Brucella melitensis, Brucella suis and Brucella abortus. OIE Rev. Scient. Techn. 32: 43-60.

Díaz R, Casanova A, Ariza J and Moriyon I 2011 The Rose Bengal test in human brucellosis: a neglected test for the diagnosis of a neglected disease. PLoS. Negl. Trop. Dis. 19: e950.

Doganay M and Aygen B 2003 Human brucellosis: an overview. Int. J. Infect. Dis. 7: 173-182.

Dominicus DAR and Akamatsu T 1989 Health policy and implementations in Tanzania. Keio J. Med. 38: 192-200.

Forbes B and Kepe T 2015 Smallholder farmers' attitudes toward the provision of drinking water for dairy cows in Kagera, Tanzania. Trop. Anim. Health Prod. 47: 415-421.

Franco MP, Mulder M, Gilman RH and Smits HL 2007 Human brucellosis. Lancet Infect. Dis. 7: 775-786.
Garin-Bastuji B, Blasco JM, Marín C and Albert D 2006 The diagnosis of brucellosis in sheep and goats, old and new tools. Small Rumin. Res. 62: 63-70.

Gusi AM, Bertu WJ, Jesús de Miguel M, DiestePérez L, Smits HL, Ocholi RA, Blasco JM, Moriyón I and Muñoz PM 2019 Comparative performance of lateral flow immunochromatography, IELISA and Rose Bengal tests for the diagnosis of cattle, sheep, goat and swine brucellosis. PLoS Negl. Trop. Dis. 13: e0007509.

IBM Corporation 2013 Statistics Package for Social Sciences Students (SPSS) IBM SPSS Statistics for Windows, Version 22.0.

Islam MR, Gupta MP, Sidhu PK, Filia G, Saxena HM and Shafi TA 2013 Comparative evaluation of indirect enzyme-linked immunosorbent assay, Rose Bengal Plate Test, microagglutination test, and polymerase chain reaction for diagnosis of brucellosis in buffaloes. Turk. J. Vet. Anim. Sci. 37: 306-310.

Jacque B, Koch-Weser S, Faux R and Meiri K 2016 Addressing health literacy challenges with a cutting-edge infectious disease curriculum for the high school biology classroom. Health Educ. Beh. 43: 43-53.

Kagera Region Investment Guide 2019 The Preparation of the Guide Was Supported by the United Nations Development Programme (UNDP) and the Economic and Social Research Foundation (ESRF).

Kandusi SE 2016 Adaptation of reverse transcription loop-mediated isothermal amplification for field diagnosis of foot-andmouth disease in Tanzania. $\mathrm{PhD}$ dissertation, Sokoine University of Agriculture, Tanzania

Kapologwe NA, Meara JG, Kengia JT, Sonda Y, Gwajima D, Alidina S and Kalolo A 2020 Development and upgrading of public primary healthcare facilities with essential surgical services infrastructure: a strategy towards achieving universal health coverage in Tanzania. BMC Health Serv. Res. 20: 1-14.

Kerr WR, Coghlan J, Payne DJ and Robertson L 1966 The laboratory diagnosis of chronic brucellosis. Lancet 2: 1181-1183.

Kifaro EG, Kasanga CJ, Nkangaga J, Joshua G, Sallu R, Yongolo M and Dautu G 2014 Epidemiological study of rift valley fever virus in Kigoma, Tanzania. Onders. J. Vet. Res. 81: 15.

Kigoma Region Socio-Economic Profile 2016 
United Republic of Tanzania President's Office Regional Administration and Local Governments.

Legesse M, Medhin G, Bayissa M and Mamo G 2018 Knowledge and perception of pastoral community members about brucellosis as a cause of abortion in animals and its zoonotic importance in Amibara District, Afar Region, Ethiopia. PloS One 13(11): e0206457.

McGiven JA, Tucker JD, Perrett LL, Stack JA, Brew SD and MacMillan AP 2003 Validation of FPA and cELISA for the detection of antibodies to Brucella abortus in cattle sera and comparison to SAT, CFT, and iELISA. J. Immunol. Meth. 278: 171-178.

Mgode GF, Japhary MM, Mhamphi GG, Kiwelu I, Athaide I and Machang'u RS 2019 Leptospirosis in sugarcane plantation and fishing communities in Kagera northwestern Tanzania. PLoS Negl. Trop. Dis. 13: e0007225.

Naing L, Winn T and Rusli BN 2006 Practical issues in calculating the sample size for prevalence studies. Arch. Orofac. Sci. 1: 9-14.

NBS (National Bureau of Statistics) 2012 Population and Housing Census. Dar es Salaam. Tanzania.

Navarro E, Casao MA and Solera J 2004 Diagnosis of human brucellosis using PCR. Exp. Rev. Mol. Diagn. 4: 115-123.

Ntirandekura JB, Matemba LE, Ngowi HA, Kimera SI, Karimuribo ED 2018 Knowledge, perceptions and practices regarding brucellosis in pastoral communities of Kagera Region in Tanzania. J. Adv. Vet. Anim. Res. 5: 343-353.

Picard-Hagen N, Berthelot X, Champion JL, Eon L, Lyazrhi F, Marois M, Peglion M, Schuster A, Trouche C and Garin-Bastuji B 2015 Contagious epididymitis due to Brucella ovis: relationship between sexual function, serology and bacterial shedding in semen. BMC Vet. Res. 11: 1-7.

$\mathrm{R}$ Core Team 2017 Version 3.4.2. A Language and Environment for Statistical Computing. $R$ Foundation for Statistical Computing.

Seleem MN, Boyle SM and Sriranganathan N 2010 Brucellosis: a re-emerging zoonosis. Vet. Microbiol. 140: 392-398.

Swai ES and Schoonman L 2009 Human brucellosis: seroprevalence and risk factors related to high risk occupational groups in Tanga Municipality, Tanzania. Zoon. Pub. Health 56: 183-187.
Tarimo PR 2017 Characterization of enteric and blood pathogens and associated factors among participants presenting with typhoid fever like symptoms in Buhigwe District Kigoma Tanzania. $\mathrm{PhD}$ dissertation, Muhimbili University of Health and Allied Sciences, Tanzania

Tchuenche JM and Bauch TC 2012 Dynamics of an infectious disease where media coverage influences transmission. Int. Scholarly Res. Notices 2012

Teng YH, Teng JJ, Chao S, Chao $\mathrm{H}$ and Waghela SD 2017 Comparison of the Rose Bengal plate and the complement fixation tests with the tube agglutination test for diagnosis of human brucellosis. Open J. Clin. Diagn. 7: 73-82.

Thickstun CR 2019 Spatial variation in risk factors for malaria in Muleba, Tanzania. PhD dissertation, University of Ottawa.

Tumwine G, Matovu E, Kabasa JD, Owiny DO and Majalija S 2015 Human brucellosis: seroprevalence and associated risk factors in agropastoral communities of Kiboga District, Central Uganda. BMC Pub. Healt. 15: 1-8.

Tuon FF, Gondolfo RB and Cerchiari N 2017 Human-to-human transmission of Brucella-a systematic review. Trop. Med. Int. Health 22: 539-546.

Vinodh R, Raj GD, Govindarajan R and Thiagarajan V 2008 Detection of Leptospira and Brucella genomes in bovine semen using polymerase chain reaction. Trop. Anim. Healh. Prod. 40: 323-329.

Weinhäupl I, Schöpf KC, Khaschabi D, Kapaga AM and Msami HM 2000 Investigations on the prevalence of bovine tuberculosis and brucellosis in dairy cattle in Dar es Salaam region and in zebu cattle in Lugoba area, Tanzania. Trop. Anim. Health Prod. 32(3): 147154.

Worthington RW, Stevensont BJ and De Lisle GW 1985 Serology and semen culture for the diagnosis of Brucella ovis Infection in chronically infected rams. New Vet. J. 33: 84-86.

Yohannes M, Gill JP, Ghatak S, Singh DK and Tolosa T 2012 Comparative evaluation of the Rose Bengal plate test, standard tube agglutination test and complement fixation test for the diagnosis of human brucellosis. Rev. Sci. Tech. Off. Int. Epiz. 31: 979-984. 